Res Mobilis

Revista internacional de investigación en mobiliario

y objetos decorativos

Vol. 7, $\mathrm{n}^{\circ} .8,2018$

\title{
LA COLECCIÓN DE NURIA PLA: UNA VIDA DE FASCINACIÓN POR EL MUEBLE \\ THE NURIA PLA'S COLLECTION: A LIFE OF FASTINATION WITH FURNITURE
}

\author{
Mónica Piera Miquel* \\ Asociación para el Estudio del Mueble
}

\begin{abstract}
Resumen
Poco a poco abren al público salas de la colección de arte de la Sra. Núria Pla, que reúne principalmente muebles españoles de la Edad Moderna. Esta magnífica noticia nos obliga a reflexionar sobre lo que supone dedicar la vida a una pasión que se vive en silencio, pero que ahora, a la vista, revela los ideales, intereses y gustos de su propietaria. Nos interesa adentrarnos en la colección, no sólo porque compartimos el interés por los muebles, sino por la excepcionalidad de la selección que, además, se conserva en un edificio singular, donde ella misma fue colocando las obras. Actualmente, la fundación responsable tiene el reto de restaurar el edificio de A. Florensa, y hacer público las dos facetas que tuvieron lugar en su interior: la colección de arte y el funcionamiento del laboratorio Ravetllat Pla que luchaba contra afecciones pulmonares y la tuberculosis.
\end{abstract}

Palabras clave: Nuria Pla, colección, muebles, escritorios, español

\begin{abstract}
Little by little the rooms of the art collection of Mrs. Núria Pla open to the public. They assemble antic furniture, mainly Spanish of the Modern Age. This magnificent news forces us to reflect on what it means to devote the life to a passion that is lived in silence, but which, now, in sight, reveals the ideals, interests and tastes of its owner. We are interested in entering the collection, not only because we share the interest in the furniture, but also because of the exceptionality of the selection, which is preserved in a singular building, where she placed the works of art herself. Currently, the responsible foundation has the challenge of restoring the building of A. Florensa and making public the two facets that took place inside: the art collection and the laboratory Ravetllat Pla that was fighting against pulmonary affections and tuberculosis.
\end{abstract}

Keywords: Nuria Pla, collection, furniture, cabinets, Spanish

\footnotetext{
*E-mail: monicapiera@estudidelmoble.com
} 


\section{Introducción}

"La manía de poseer y coleccionar antigüedades es una enfermedad incurable. Ni la homeopatía, ni las hierbas milagrosas, ni los tratados de física, ni de moral, son eficaz remedio, ni lenitivo siquiera, para el que se siente inclinado a conservar lo que ha conservado el tiempo. Con tal manía nacemos, los que nacemos con ella y con ella marchamos tan campantes a la tumba". "Para tener en veneración un objeto hay que haberle hecho la corte, haberlo deseado desde tiempo y así se le estima en proporción de los trabajos y sinsabores que cuesta" ${ }^{1}$.

Los coleccionistas son personas que dedican una parte o toda la vida a agrupar un tipo de objeto natural o elaborado que previamente han seleccionado. Bien, no siempre previamente, porque a menudo las colecciones se crean sin que el protagonista tenga inicialmente conciencia de que la está formando. Empieza a interesarse por una pieza, después por otra, más tarde por una tercera que es mejor que las anteriores; así que, poco a poco, ha dado los primeros pasos hacia una colección. El comprador se ha convertido en un coleccionista, en un buscador de tesoros, entrando en una nueva faceta como consumidor. Sin darse cuenta, quedará atrapado por aquel asunto y, al menos por un tiempo, en un apasionado del tema.

Desde elementos que nos ofrece la naturaleza a objetos realizados por el hombre, un coleccionista fija la vista en algo que le acaba atrapando. Desde algo tan insignificante como un tapón de botella a las pinturas y joyas más valiosas, todo es susceptible de ser coleccionable. La historia nos lo ha demostrado. La curiosidad es la mecha que lleva al conocimiento, igual que esa ansia de conocimiento lleva al de posesión.

A menudo, esos buscadores de tesoros dedican su energía en la soledad, sin posibilidades de compartirla con nadie, disfrutando y sufriendo por esas piezas que dan sentido a su día a día. Las obras que configuran una colección se buscan una a una, con paciencia y sin estridencias. El coleccionista se puede mover por la razón, pero sobre todo por sentimiento y emoción. Llega a crear un vínculo tan estrecho con los objetos que ha adquirido que podríamos hablar de verdadero lazo afectivo, incluso de culto al objeto, como titulamos una de las publicaciones de la Asociación para el Estudio del Mueble dedicada al tema ${ }^{2}$.

La obra de colección pierde conexión con todo uso práctico que podía haber tenido cuando fue creado, para ascender a documento de un tiempo y un lugar, pero sobre todo a asunto de admiración. Porque coleccionar significa, sobre todo, seleccionar y escoger bajo unos criterios que el propio autor decide. La mayoría de coleccionistas no acumulan para aumentar el número de posesiones, sino para conseguir la variedad y la rareza, para llenar vacíos y crear series. A medida que se avanza en la configuración de la colección, él, el coleccionista, acaba dominando el tema y se convierte en muchas ocasiones en el mejor experto en la materia. 
Pero, a diferencia de los historiadores, que se nos exige rigor y racionalidad, aunque podamos ser apasionados en un tema, en el coleccionista los vínculos afectivos juegan un papel fundamental y él puede dejarse llevar por ellos libremente. Se maravilla ante la pieza, disfruta con ella y le gusta compartir sus sentimientos con otros que entiendan y no cuestionen su pasión. Suelen ser buenos conversadores de sus trofeos, sobre todo del proceso de seducción, cortejo y logro del botín. El conocimiento que acumulan es de gran interés para los estudiosos, y debemos aprovecharlo, labor ésta nada fácil, porque, digámoslo con franqueza, su enamoramiento suele ser ciego; impidiendo ese necesario análisis objetivo y racional del historiador.

Habitualmente es difícil que los que coleccionan abran las puertas a extraños, porque reniegan de los que se inmiscuyen y de los que banalizan o critican su dedicación. Pocos son los que hablan abiertamente de sus gustos, racionalizan las compras y dan pistas claras sobre la selección, como hace Mario Praz a quien las obras "entran en su vida" y la transforman, como explica en $L a$ casa de la vida.

En la colección, las obras pierden definitivamente el contexto originario para penetrar en otro mundo donde tienen la oportunidad de tomar una nueva consideración, a menudo más relevante. Escogidas a consciencia, se puede parar el reloj de su tiempo y salvarlas de la indiferencia, de la desaparición y de la pérdida, porque el antónimo de coleccionar es desperdigar. En este sentido, los coleccionistas son salvadores de obras y algunos de ellos coolhunters, porque sus decisiones inciden en los gustos y en el mercado del arte.

$\mathrm{Al}$ coleccionista de antigüedades le puede interesar poseer un cachito de pasado, un mordisco de otra época, un pedazo de un mundo que ya no volverá. A la que avanza en sus capturas, exigirá que estos tesoros sean de más alta calidad y más puros; es decir que ofrezcan la excelencia dentro de su presupuesto.

Podríamos concluir que una colección es un conjunto de obras seleccionadas por una persona bajo unos criterios de calidad, excepcionalidad y singularidad, y desde entonces serán cuidadas y admiradas. Por ello, la colección es el reflejo del propietario que la creó. En la conservación y valoración del patrimonio, el coleccionismo juega un papel determinante.

Aunque, como decíamos, todo puede ser susceptible de ser coleccionable, las colecciones de muebles no son nada comunes. Todos tenemos muebles en casa, pero no por ello somos coleccionistas. Es un objeto grande de dimensiones, que ocupa espacio, difícil de conservar, poco valorado en el mundo de las Bellas Artes, con un conocimiento minoritario y pocos especialistas que difundan su interés.

La dificultad del espacio provoca que en muchas ocasiones los muebles escogidos se sigan utilizando o que se les busque una salida práctica, lo que los distingue de la mayoría de obras de colección, que dejan de perder la función utilitaria para la que se concibieron. Pensamos, por ejemplo, en la cerámica, los abanicos o el vidrio. Mantener los muebles en uso demuestra su adaptación al paso del tiempo, pero acentúa su degradación y puede provocarles alteraciones. Además, el hecho de que la materias básicas con las que han estado construidos 
hasta el siglo XX sean madera y tejido ha causado naturales pérdidas, desintegraciones y dificultades de conservación. Todo ello conlleva dificultades a la hora de que el mueble sea escogido como objeto de colección, siendo la colección de arquetas, la más común, por su variedad artística y pequeño tamaño ${ }^{4}$.

\section{La colección de la Sra. Nuria Pla}

La señora Nuria Pla Montseny (1916-2011) ha cumplido con todas las premisas para ser considerada una verdadera coleccionista de Barcelona, principalmente de muebles. Decía ella que había heredado la sensibilidad por el arte de su madre, aunque su abuelo ya era coleccionista de cromos, que ella conservaba en álbumes que dejaba abiertos sobre sus mesas antiguas. El trabajo de coleccionista lo realizó sola, ya que su marido Alfonso Carro Crespo, fiscal general de la Audiencia de Girona, no tenía especial interés por los muebles.

Nuria Pla era una persona culta, discreta, activa y de ideas claras. Una de las primeras médicos de España en una época en la que para las mujeres estudiar era poco común. Tenía que haberse licenciado en 1937, si bien la Guerra Civil hizo que se prolongara la carrera hasta el año 1940. "Una guerra civil es lo peor que puede pasar. Fue horroroso" comentaba ella.

Estudió la carrera para trabajar en el Instituto Ravetllat-Pla con su padre, el doctor en medicina Ramon Pla Armengol (1880-1958). Él comercializó dos productos antituberculosos (hemo-antitoxina y Suero Ravetllat-Pla) que extraía de la sangre de los caballos. Creó el instituto junto con el veterinario Joaquim Ravetllat i Estech (1871-1923) y, a la muerte de éste, fue el único propietario. Con el tiempo consiguió comercializar los dos productos en unos 20 países, especialmente en Latinoamérica y creó una red innovadora internacional científico-comercial. El instituto sobrevivió hasta 1980. La biblioteca y el archivo del Instituto fueron donados por su única hija, Nuria Pla, a la Unidad de Historia de la Medicina de la Universidad Autónoma de Barcelona ${ }^{5}$.

El laboratorio y la vivienda familiar convivían en un enorme edificio de cuatro plantas noucentista, construido por el eminente arquitecto Adolf Florensa, quien visualizó en las fachadas los dos usos, al diseñarlas con estéticas bien diferenciadas. Si la cara de la vivienda evoca la masía tradicional catalana, el laboratorio busca sus raíces en las villas renacentistas italianas. En el edificio se conservan las salas del instituto -desde donde se extraía la sangre de los caballos hasta donde se embalaban los productos para ser distribuidos-, el instrumental, maquinaria y muebles que explican el funcionamiento de este destacado centro al servicio de la medicina durante más de cinco décadas del siglo XX. Además de la colección de muebles, es importante que este patrimonio científico, que ocupa una buena parte del edificio, no sólo no se pierda sino que se restaure y se haga público.

Como decimos, la sede del Instituto Ravetllat-Pla es también el contenedor de la biografía de la señora Pla, ya que ella vivió, trabajó, coleccionó y murió en él. Un espacio donde transcurrió su existencia y compartió sus intereses con 
aquellos que acudieron a verla. Si empezó la colección por renovar el mobiliario de la vivienda familiar situada en la planta noble, poco a poco, las salas del instituto le proporcionaron el espacio necesario para ubicar las adquisiciones, tanto los muebles como las piezas de orfebrería y escultura, que suman en total unas 850 piezas $^{6}$.

Nuria Pla se dedicó intensamente a buscar muebles, en total 630, cosa que es sin duda algo extraordinario. Decía que la afición es lo que le movía y lo que le hizo llegar a adquirir tantas obras. Su ojo clínico lo aprendió a partir de una formación práctica. Su formación médica le debió facilitar el método de análisis, la diagnosis de las obras y la toma de decisiones. En contacto con las piezas, no dudaba en desmontarlas para conocer sus entrañas y asegurar su antigüedad. Una dedicación que también le hacía sufrir cuando no podía satisfacer sus deseos, ya que, como a todo coleccionista, las cuestiones económicas le llevaron a no poder comprar piezas que le interesaban. Ella misma reconocía que su defecto era el apasionamiento que, en esta como en otras cosas, le llevó a entregarse en cuerpo y alma, llegando a hacer disparates y equivocaciones.

Entre sus intereses se contaba el de las matemáticas y es así que a partir de números explicaba los éxitos y los fracasos de la colección. Decía que de diez piezas que ella compraba, ocho eran corrientes, una sobresalía de la media y en cambio, una quedaba por debajo. Con el tiempo uno debe saber vender las que no son tan buenas para mejorar el nivel general de la colección, añadía. Esta compra-venta necesaria la hizo a lo largo de los años. El interés por las matemáticas permite entender que también dominara el piano y que fuera profesora de este instrumento. Cuando le preguntábamos qué música le gustaba, sin dudarlo, decía que la preferida era la de J. S. Bach.

Abría la casa a aquellos que no fueran "lejanos de ideas", como diría educadamente M. Praz. Una vez dentro, uno descubría como su prodigiosa memoria le permitía recordar los detalles de cada una de las obras que llenaban el edificio. Sin verlas era capaz de describir minuciosamente cada detalle y destacar aquel elemento que diferenciaba ese mueble de cualquier otro de la colección.

Aunque contaba con una buena muestra de tallas (77) y objetos de orfebrería (100), sin duda, el conjunto único es el de muebles. Recordaba hasta el final de su vida dónde y cómo adquirió cada una de las piezas y sabía, como nadie, la calidad, el valor y el sentido de cada uno de las obras que integraban la colección. Ella compró y también estudió lo que compraba. Autodidacta, aguda, rápida, reflexiva mostraba un envidiable conocimiento de la materia.

\section{La colección de muebles}

La colección de la Sra. Pla debe ser la más importante de mueble español del Renacimiento y Barroco. Al menos nosotros no conocemos ninguna que la supere en número y variedad en las series escogidas. 
Ella misma definía los objetivos de la colección: reunir las mejores piezas de mueble español de los siglos XVI y XVII, los dos siglos en los que España fue importante a nivel internacional y aportó mayor creatividad e innovación al mobiliario. En el siglo XVIII, añadía, España ya se dedica a copiar las novedades de fuera y a menudo con resultados poco interesantes. Aun así, el número de muebles del siglo XVIII es destacado, pero no hay piezas del siglo XIX compradas a consciencia. Bajo estas premisas, observamos que en la selección domina todo aquello que podríamos considerar tradicional, propio de los territorios, que ha ido perviviendo y a la vez evolucionando de generación en generación. Ese mantenerse en las raíces dificulta el mismo estudio de las obras, siempre anónimas y de difícil datación.

Hay ejemplares de todas los territorios, con variedad de modelos de cada una de las tipologías importantes de mueble con el objetivo de poderlas estudiar. Aunque se compone de ejemplares que quizás en el primer vistazo consideraríamos populares; en realidad, son muebles construidos en talleres locales para las casas acomodadas de pueblos y ciudades de la Época Moderna. Destacan las rarezas, es decir muebles excepcionales, ya sea por la tipología, estructura, decoración o forma. (Fig. 1)

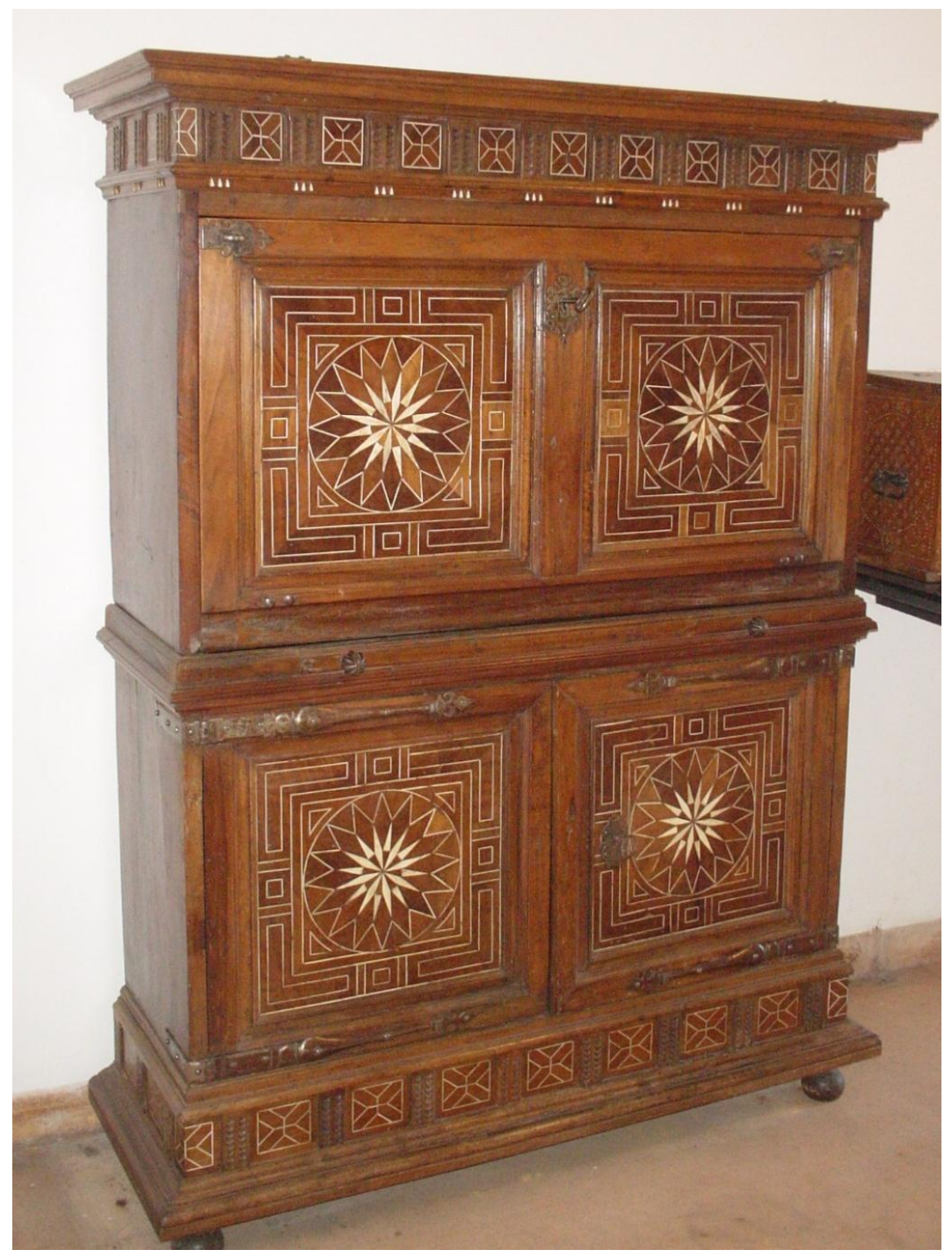

Fig. 1 Escritorio de Valencia, siglo XVII, realizado en dos cuerpos a juego, decorados en nogal y hueso a partir de estrellas de dieciséis puntas, motivo que se repite en muebles de Levante en épocas posteriores. 
Si sabemos que para entender los muebles es necesario tener diversos ejemplares del mismo modelo, atender a sus diferencias y apreciar sus calidades, esto lo hizo a conciencia con las tipologías más importantes de mueble español. A partir de los muebles escogidos por la Sra. Pla se puede realizar un estudio evolutivo de cada una de estas tipologías (escritorios, mesas, camas, sillas), así como apreciar diferencias formales de los distintos centros de producción. De todas maneras, se ha de comentar, que la facilidad intrínseca al objeto que tiene el mueble para ser movido da muchos problemas para reconocer el lugar de producción con precisión y seguridad. La falta de documentos y de publicaciones agrava el problema de catalogación. En el caso de esta colección, se cuenta únicamente con los comentarios e informaciones que la propietaria ha podido aportar. El estudio de la colección por parte de expertos en historia del mueble de cada uno de los distintos territorios nos parece la mejor manera para catalogar las obras con precisión, así como para confirmar las propuestas que ella ha dejado anotadas.

Para la Sra. Pla una gran parte del atractivo del mueble es su valor táctil. Como ella a menudo comentaba, el mueble se ha de mirar, pero se ha de tocar; tanto para disfrutarlo como para reconocer lo bueno de lo falso. Acariciar la madera -cálida, gastada por el paso del tiempo y del uso- es un placer que nos ofrece el mueble antiguo y que ella supo transmitir. Reconocía el mueble como obra de arte, con la que se consigue una conexión emocionante y cercana, más acentuada que cualquier magnífico cuadro. En realidad, creemos que tenía predilección por las obras tridimensionales, esas que aportan volumen, como los muebles, las tallas y los objetos de plata. Ese interés permitiría entender la elección de obras, donde no hay lugar para obras planas, como son las pinturas.

Además, la coleccionista compartía el interés del mueble como fuente de información histórica. Como es bien sabido, a través de los muebles nos podemos acercar a la manera de vivir y pensar de una determinada sociedad. Las proporciones son una característica clave para reconocer cómo se usaban las obras y, por ello, coincidimos con la coleccionista en que los muebles se han de apreciar y estudiar en directo. Aunque ahora las obras están descontextualizadas de su lugar de uso, recuperar esa relación y conocer cómo, dónde y quién las usaba nos da una información clave para entender cada una de las obras de la colección, pero, sobre todo, nos explica datos esenciales para reconstruir esa historia de la vida cotidiana y doméstica de los distintos territorios que pueblan España.

Las tres tipologías más notables de la colección son los escritorios, las alacenas y las mesas. Tres muebles que tienen un esencial desarrollo por todo el territorio en la Edad Moderna, lo que obliga a su conocimiento para entender la evolución del mueble histórico ${ }^{7}$.

La primera pieza que compró fue un bargueño, nombre del siglo XIX que ella todavía utilizaba para referirse al escritorio de columnillas castellano. Lo hizo porque consideró que era el mueble más característico de España. El interés por la tipología la mantuvo hasta el final de su vida, ya que fue también una de las últimas piezas en comprar. Podemos decir que su selección -92- escritorios es 
inmejorable. La mayoría castellanos, pero con interesantes ejemplares de la Corona de Aragón, cordillera cantábrica y uno excepcional granadino del siglo XVI trabajado en taracea. Todos sabemos lo difícil que es localizar pies de escritorio desmontables originales, ya que en $\mathrm{su}$ gran mayoría son reinterpretaciones del siglo XIX. Ella consiguió reunir 30 ejemplares, de original diseño, que sirven de soporte a algunos de los escritorios.

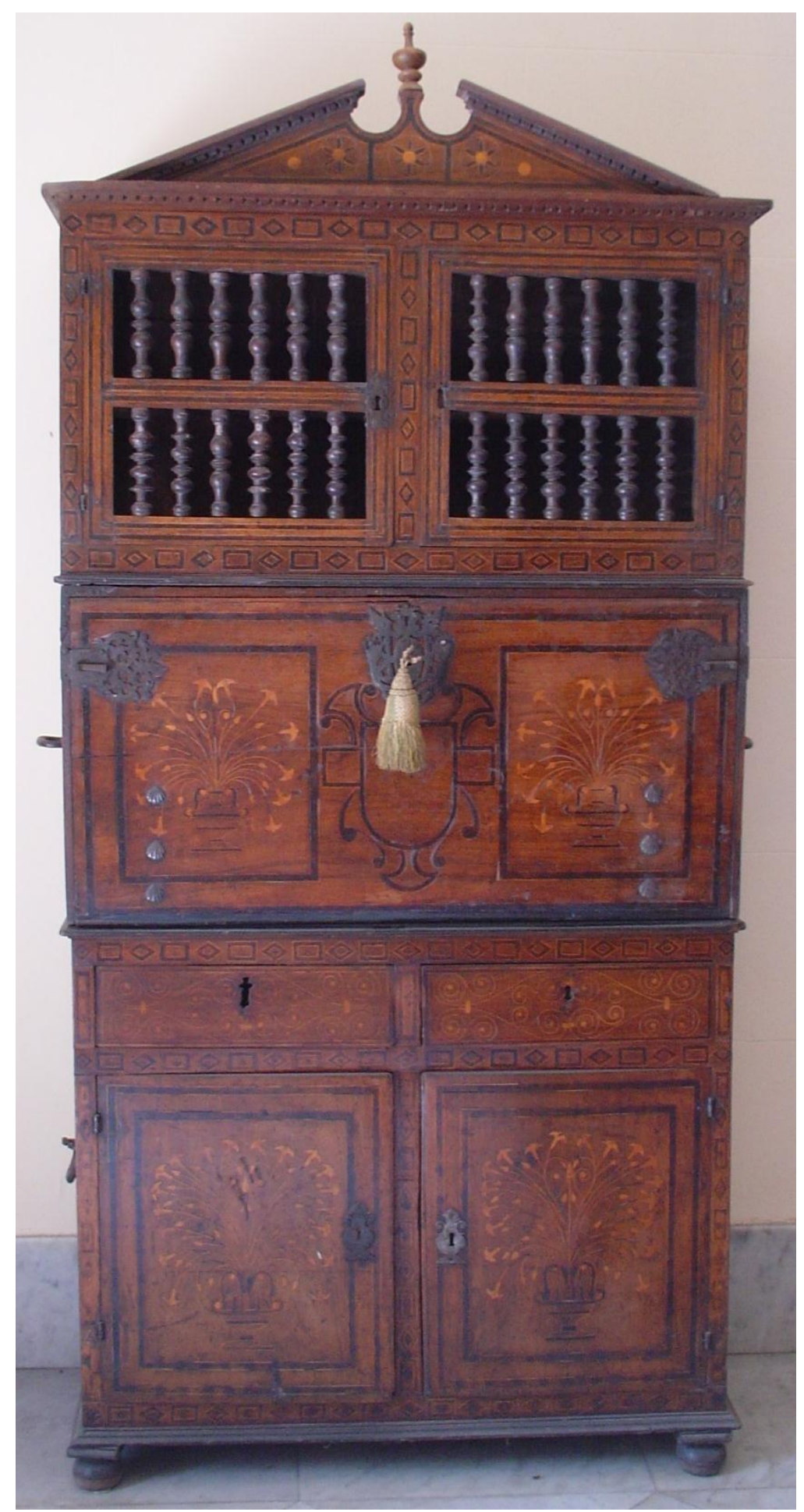

Fig. 2. Alacena escritorio, Asturias, siglo XVII, de una tipología común en la zona que superpone diferentes usos: alacena, escritorio, cajones y puertas de armario. Está decorado con taracea de motivos vegetales, jarros con flores y en el centro del escritorio, un escudo mudo. 
Si la importancia del escritorio de Salamanca es un hecho conocido y compartido por los historiadores del mueble; ya que era, sobre todo, un mueble de representación presente entre los bienes de familias nobiliarias, la otra tipología seleccionada por Nuria Pla, nada común en otras colecciones de arte, es la alacena, recogiendo un total de 64 ejemplares entre alacenas y armarios. (Fig. 2)

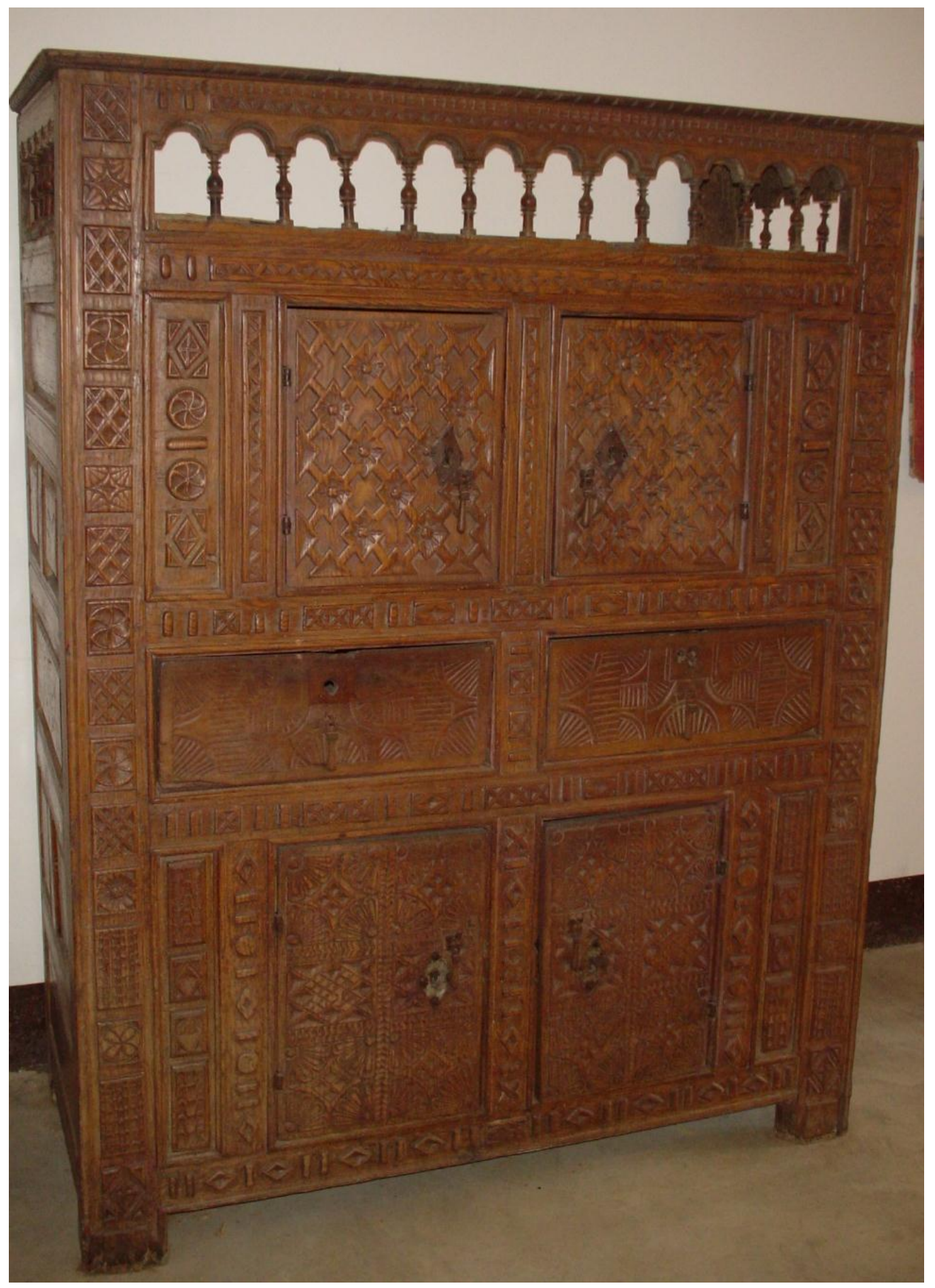

Fig. 3. Alacena de Salamanca, coronada por una arquería y con el frente trabajado con talla sobre macizo plana con motivos geométricos de larga tradición, como discos giratorios, flores circulares, cruces y rombos. 
Es el mueble para guardar la comida, característico del siglo XVII que continua en el siglo XVIII y que a ella le interesó porque, decía, mantenía la tradición sin imitar la producción foránea. Los carpinteros de los diferentes centros diseñaban las alacenas a su manera, siguiendo métodos y formas aprendidos de padres a hijos. Eso convierte a la alacena en testimonio de lo "esencial", de esa creatividad arraigada a la propia tierra que se transmite generación a generación. Si el modelo más característico es el de León y Salamanca con dos puertas altas, dos bajas y cajones en medio (Fig. 3); la colección nos permite descubrir como esta composición se mantiene sólo en algunos pocos ejemplares, ya que la mayoría de armarios alacena construidos en España modifican estas formas básicas. (Fig. 4) Argumentaba la Sra. Pla, al respecto, que en las zonas frías la alacena no necesitaba celosía y se podía guardar la comida con puertas cerradas, dificultando su diferenciación del resto

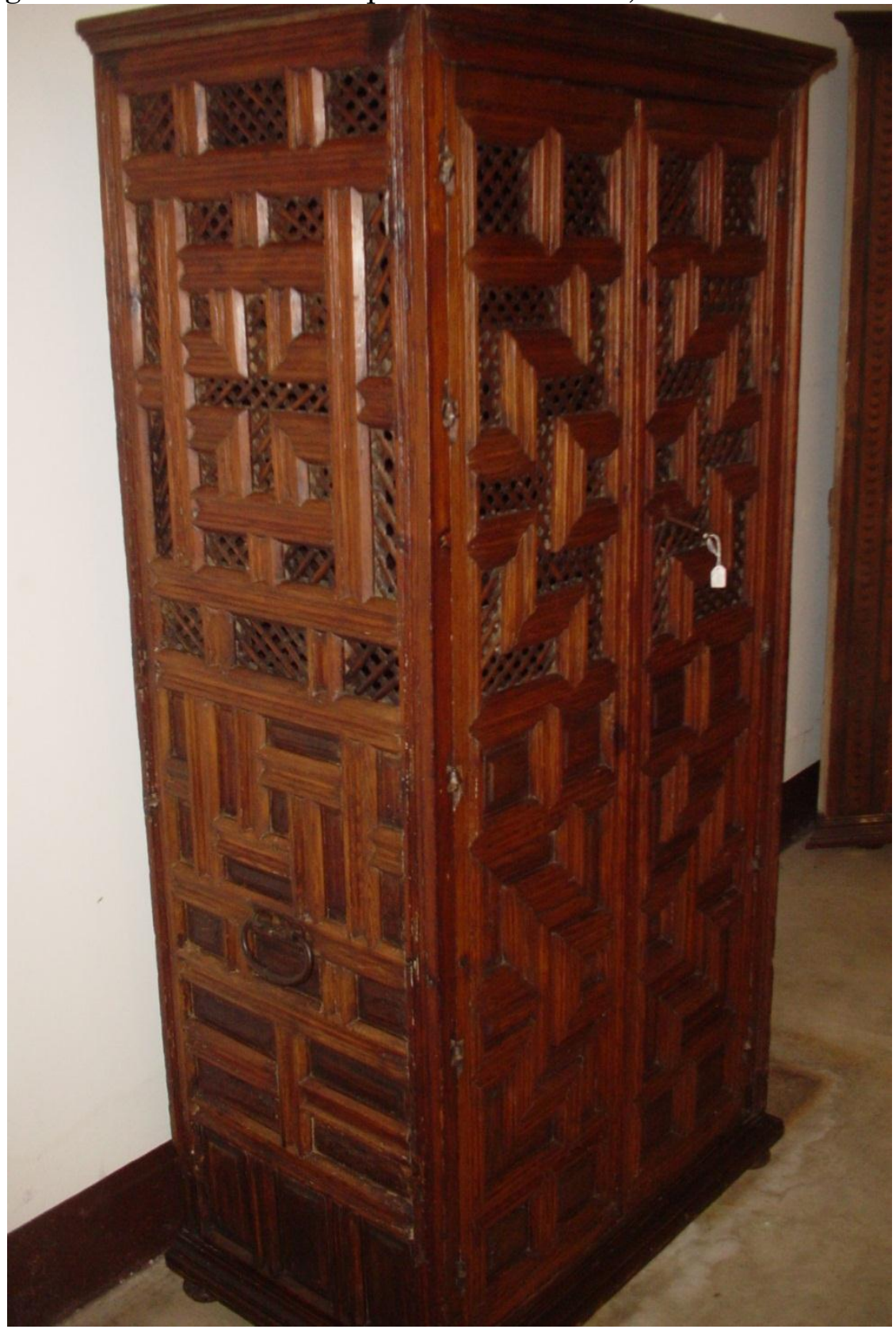
de armarios. (Fig. 5) En cambio, en tierras cálidas, la celosía se hace necesaria. Entre todas las variedades tipológicas, destaca una alacena aparador con estantes escalonados de la Rioja, cercano al modelo del tinell catalán.

Fig. 4. Armario alacena andaluz en pino, trabajado con cuarterones y un magnífico trabajo en la celosía que ocupa el frente y los costados. 


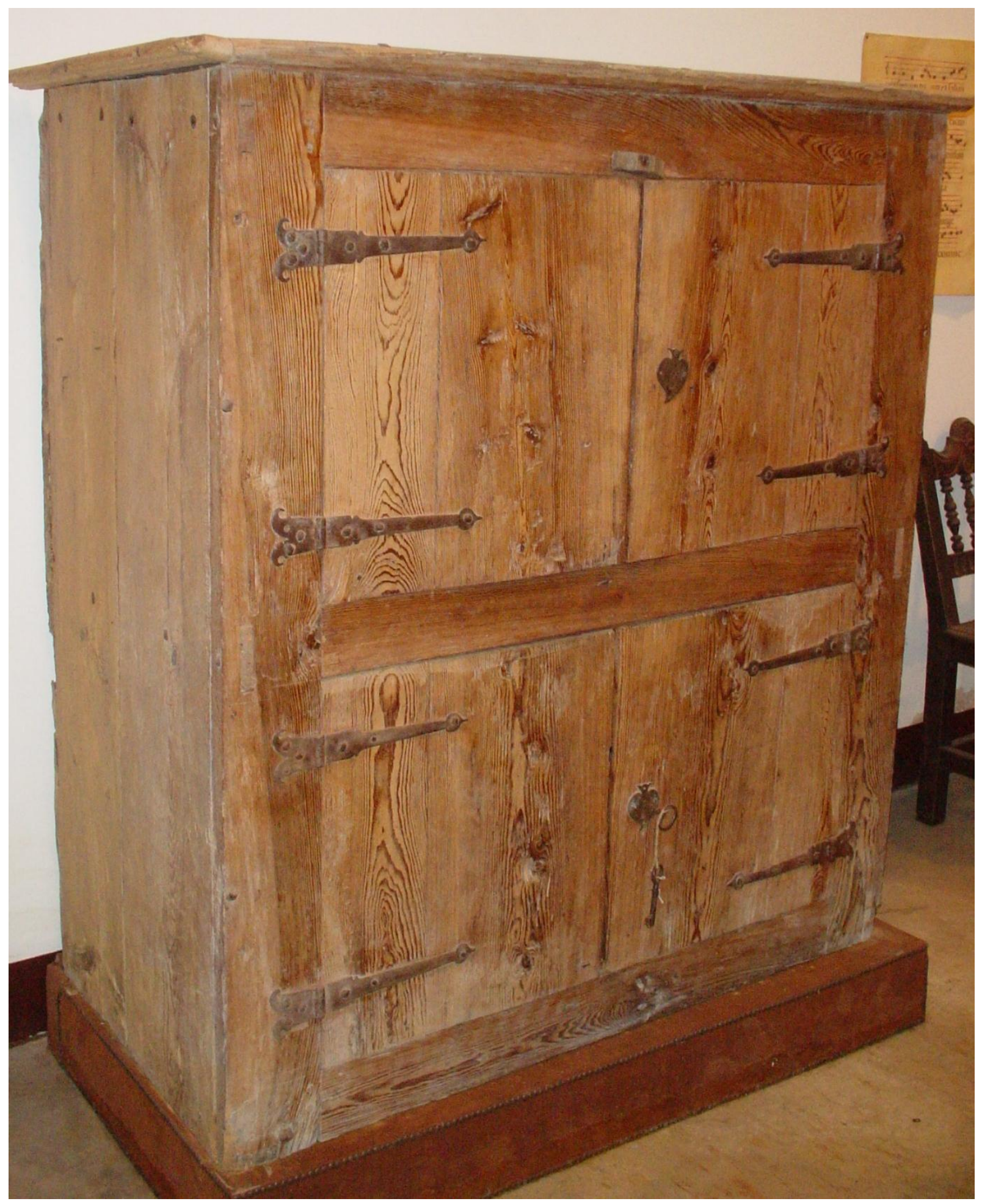

Fig. 5. Armario de Calatayud construido en pino con sencillamente clavados a un armazón de montantes y traveseros. Sólo las bisagras destacan sobre su estructura. 


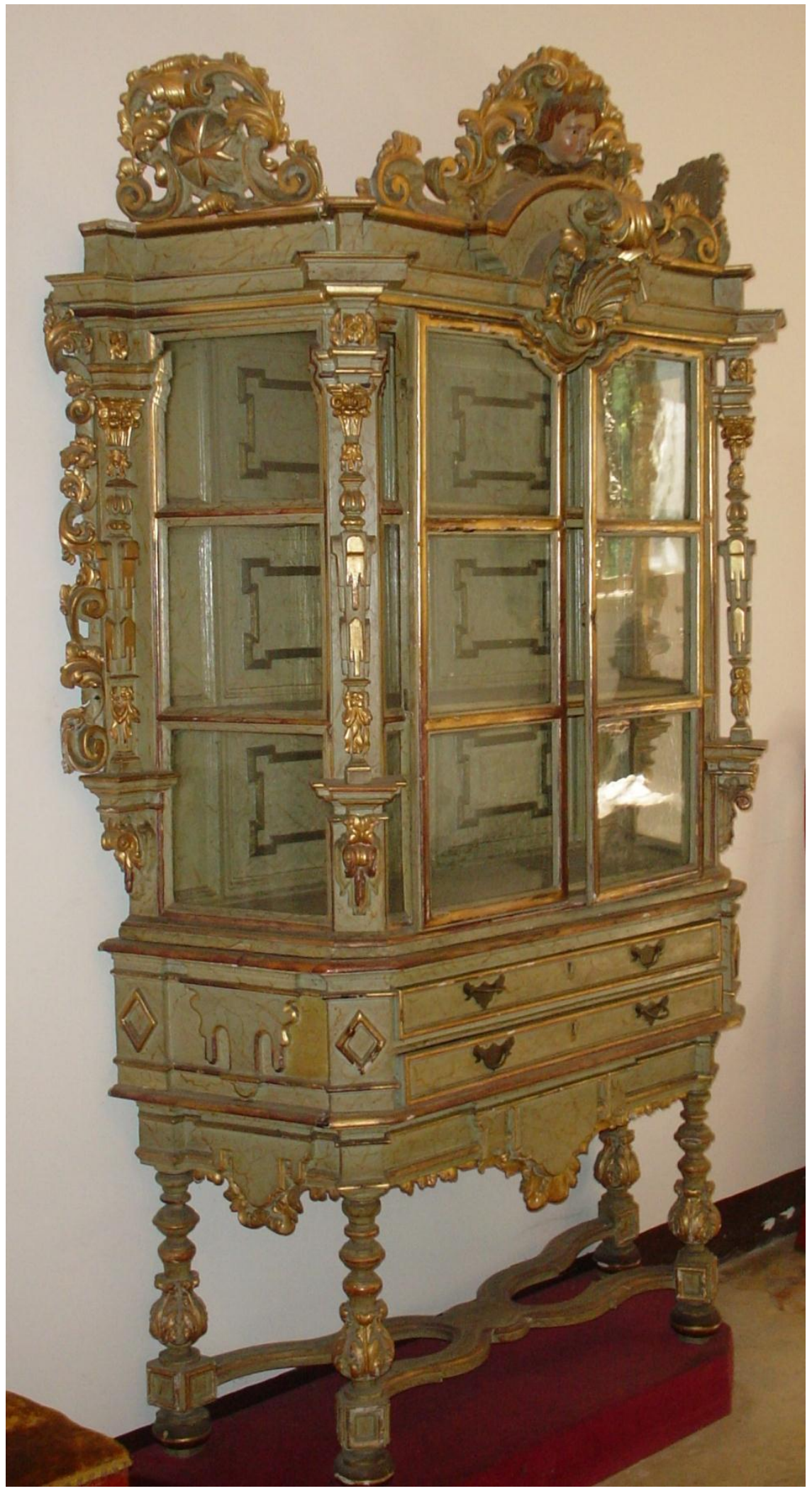

Fig. 6. Escaparate de Andalucía, siglo XVIII, que incluye la cruz de Malta, tallado, jaspeado y dorado a la manera de los retablos del territorio. 
Además de estos dos tipos de mueble, como arcas y escaparates, (Fig. 6) también es destacable la recopilación de mesas (109) y asientos (157). A citar, el atrevido banco andaluz del siglo XVIII y otro de la misma época procedente, según ella contaba, de la Capilla Real de Granada; así como las camas, con el magnífico y ligero ejemplar de campaña castellano.

La mesa española basa su estructura con dos conceptos claros: la practicidad y la solidez. Construidas mayoritariamente en nogal y con las patas fijadas por tirantes de hierro, se idearon originalmente en el siglo XVI para poder ser dobladas y transportadas. La señora Pla conserva una que tiene todavía el taco para que el desgaste con el fregamiento del suelo no afectara a las partes torneadas, y muchas otras que cambian en la forma de la pata, la composición de la cintura - con o sin cajones- o las proporciones y medidas. La mesa española es "bonita" decía, adjetivo que utilizaba a menudo como sinónimo de elegante. Belleza que se refería, también, a un mueble inteligente, sólido y ligero, resultado de combinar sólo dos materiales, el nogal y el hierro. Aunque todas las mesas parecen iguales, cada una es diferente, y es en ese interés por el detalle que radica el atractivo de esa original y extraordinaria colección de mesas. (Fig. 7)

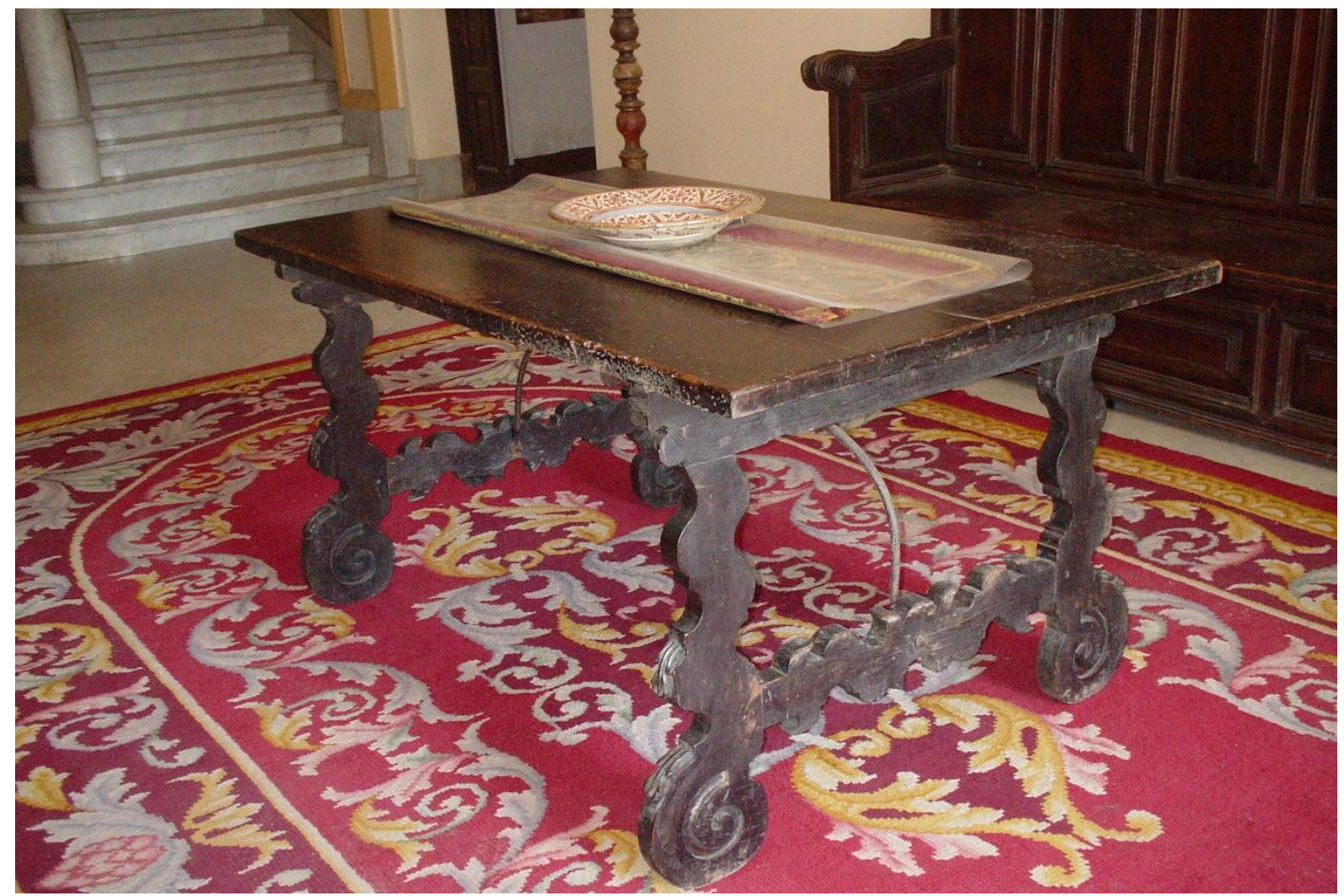

Fig. 7. Bufete con patas sinuosas y talladas, del siglo XVII o inicio del siguiente, procedente de la Rioja. 
Quizás es en los asientos donde mejor se observa el equilibrio entre tradiciones locales e influencias foráneas. Entre los 157 ejemplares que pueblan la casa, hay de todo, pero principalmente sillas, sillones y bancos, asientos de madera y asientos de cuero. En cambio, no penetra en los modelos tapizados franceses del siglo XVIII, aquellos que aportaron comodidad al cuerpo y son la máxima expresión del asiento histórico en cualquier colección. Igualmente que en el resto de tipologías, los gustos e intereses de la Sra. Nuria Pla quedan bien enmarcados en aquello que representa el asiento doméstico regional y en un puñado de obras extranjeras, especialmente aquellas que influenciaron en la producción peninsular. (Fig. 8)

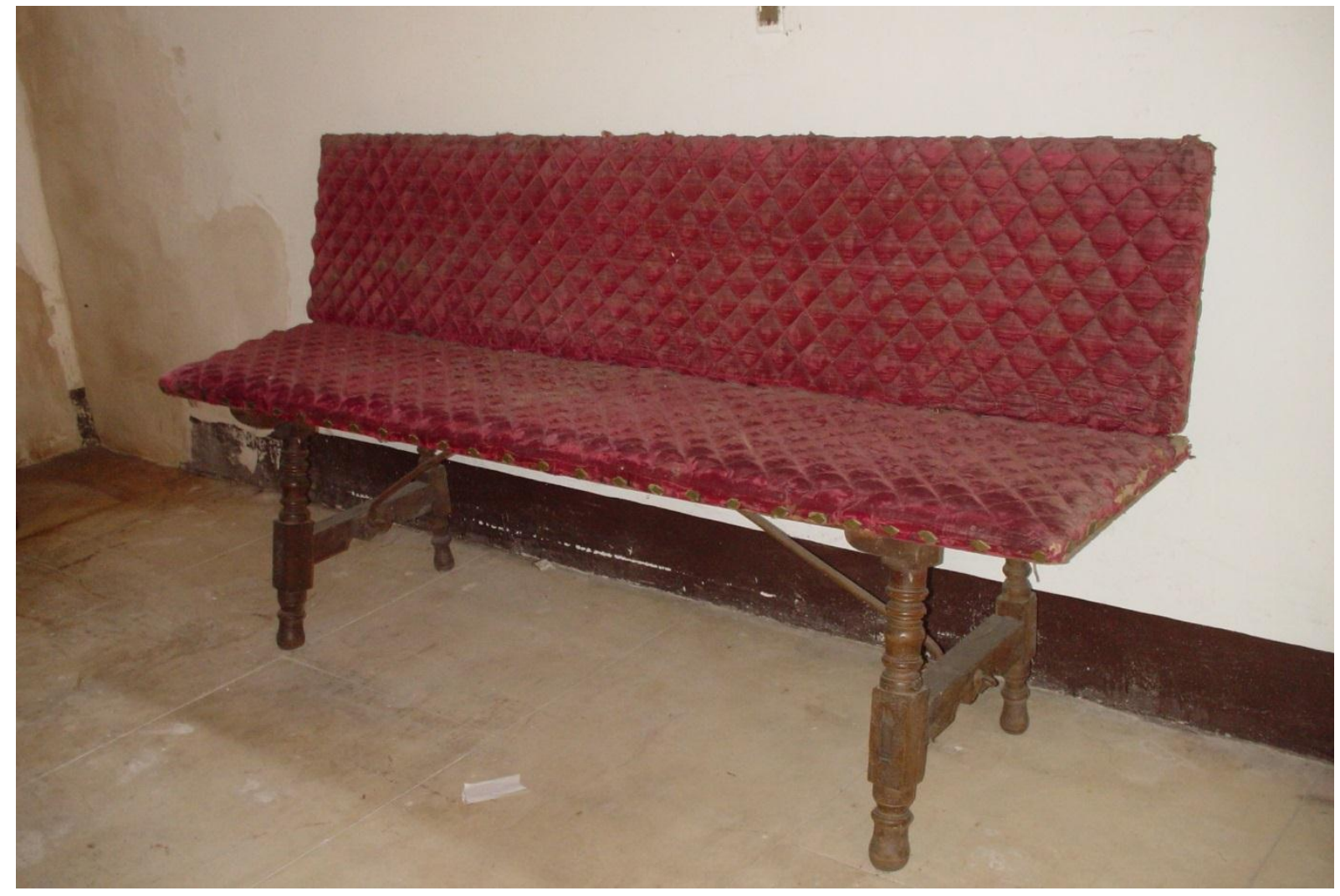

Fig. 8. Banco de libro del siglo XVII, henchido en terciopelo y con patas torneadas, procedente de la Universidad de Salamanca.

La colección es muy rica en muebles españoles, sobre todo castellanos, pero también del Levante, Andalucía, Navarra, Mallorca, etc. Para ella, la mejor producción estaba en Castilla y Andalucía. Castilla por su pureza y elegancia de proporciones; Andalucía por la creatividad y atrevimiento de formas y decoración. El mueble catalán está representado con una buena selección de camas de los siglos XVII y XVIII, así como con alguna cómoda, escritorio, armario y tocador. Se lamentaba de no haber podido conseguir una arca con cajones gótica, el mueble por excelencia de Cataluña, que no estuviera excesivamente tocada. Por ello, y a pesar de las ofertas que tuvo, falta en la colección ${ }^{8}$. 
La policromía es una técnica con una alta presencia. La pintura es a menudo un recurso decorativo más económico que la talla o la marquetería. Las maderas blandas se pintan para protegerlas, pero las policromías decoran, imitan otros materiales o transmiten mensajes. Repasando la colección, encontramos escritorios, alacenas y mesas policromadas, pero también muchos otros muebles, algunos de los cuales procedentes de otros países. Y es que aunque la colección tuvo como primer objetivo la selección de mueble español, con el tiempo fue adquiriendo obras de muchos otros territorios, especialmente aquellos que mostraban maneras de hacer originales. Taraceas mexicanas y alemanas, policromías italianas, tallas alpinas (Fig. 9) y marqueterías holandesas, conchas virreinales, napolitanas y flamencas, entre muchas otras propuestas. El mueble extranjero no era un objetivo prioritario, pero acabó teniendo un conjunto de piezas de extraordinaria calidad. Entre ellas, el escritorio napolitano datado en 1609 que, según revela $\mathrm{M}^{\mathrm{a}}$. Paz Aguiló, podría haber estado propiedad del virrey Juan Alfonso de Pimentel'.

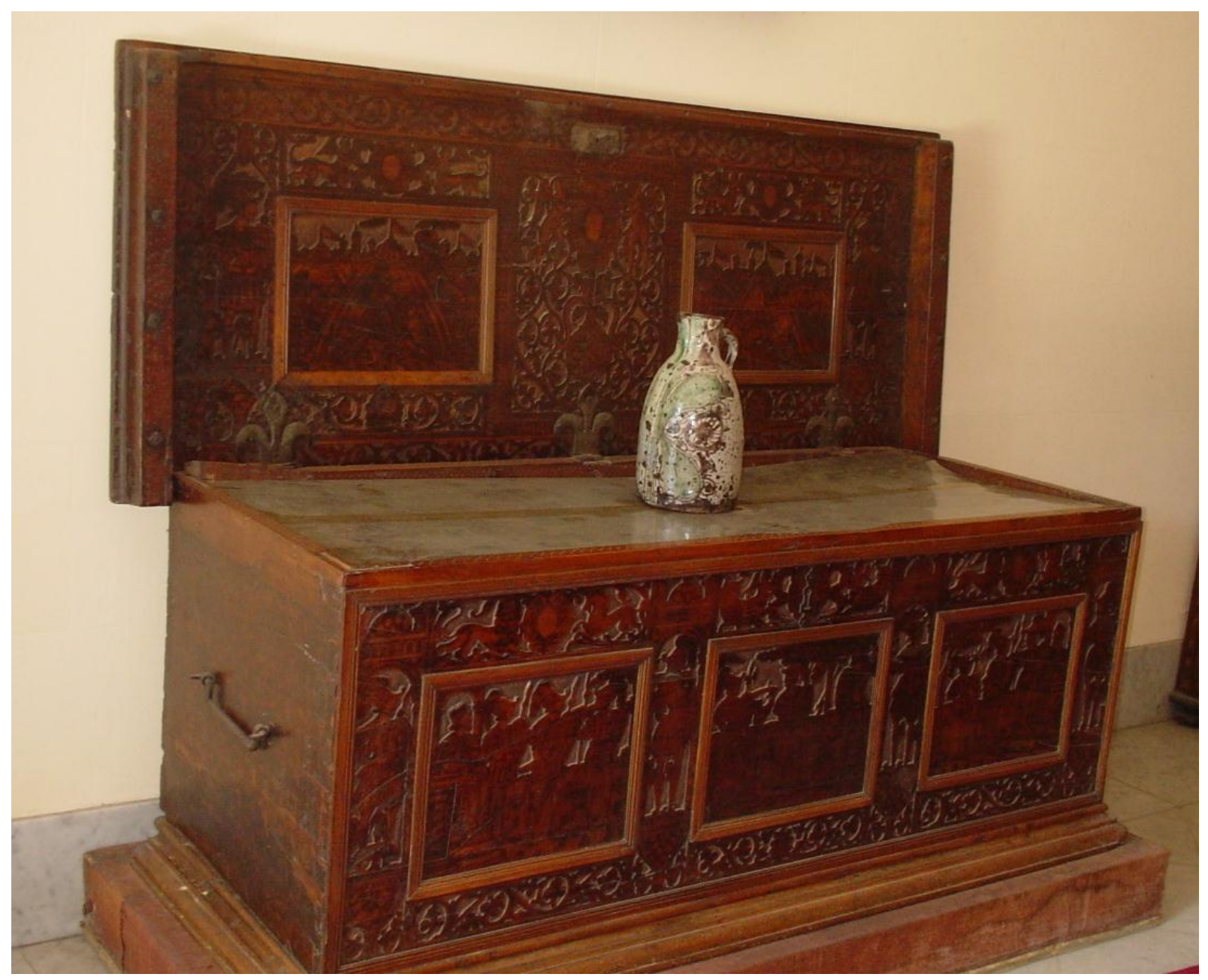

Fig. 9. Arcaz en cedro tallado y tintado con escenas clásicas, trabajo propio de las regiones de los Alpes, especialmente del Alto Adigio. 
Dentro de las técnicas pictóricas, destaca la colección de obras decorada en lacca contrafatta o laca povera. Inventada en Venecia en el siglo XVIII para obtener muebles policromados a un precio inferior que el de la laca veneciana, obtuvo un éxito fácil. Con la técnica de recorte de grabados iluminados, encolados sobre un fondo policromado y protegido el conjunto por capa de sandáraca, se ofrecía un resultado sumamente atractivo, aunque rápido y más económico de realizar que los trabajos de charol. La técnica se extendió por la Península Italiana y de allá pasó a las Baleares y también a la costa ibérica, penetrando en Andalucía, Valencia, Cataluña y Aragón. De todos estos centros hay piezas en la colección, que permitirían llevar a cabo un estudio monográfico de un campo todavía muy desconocido.
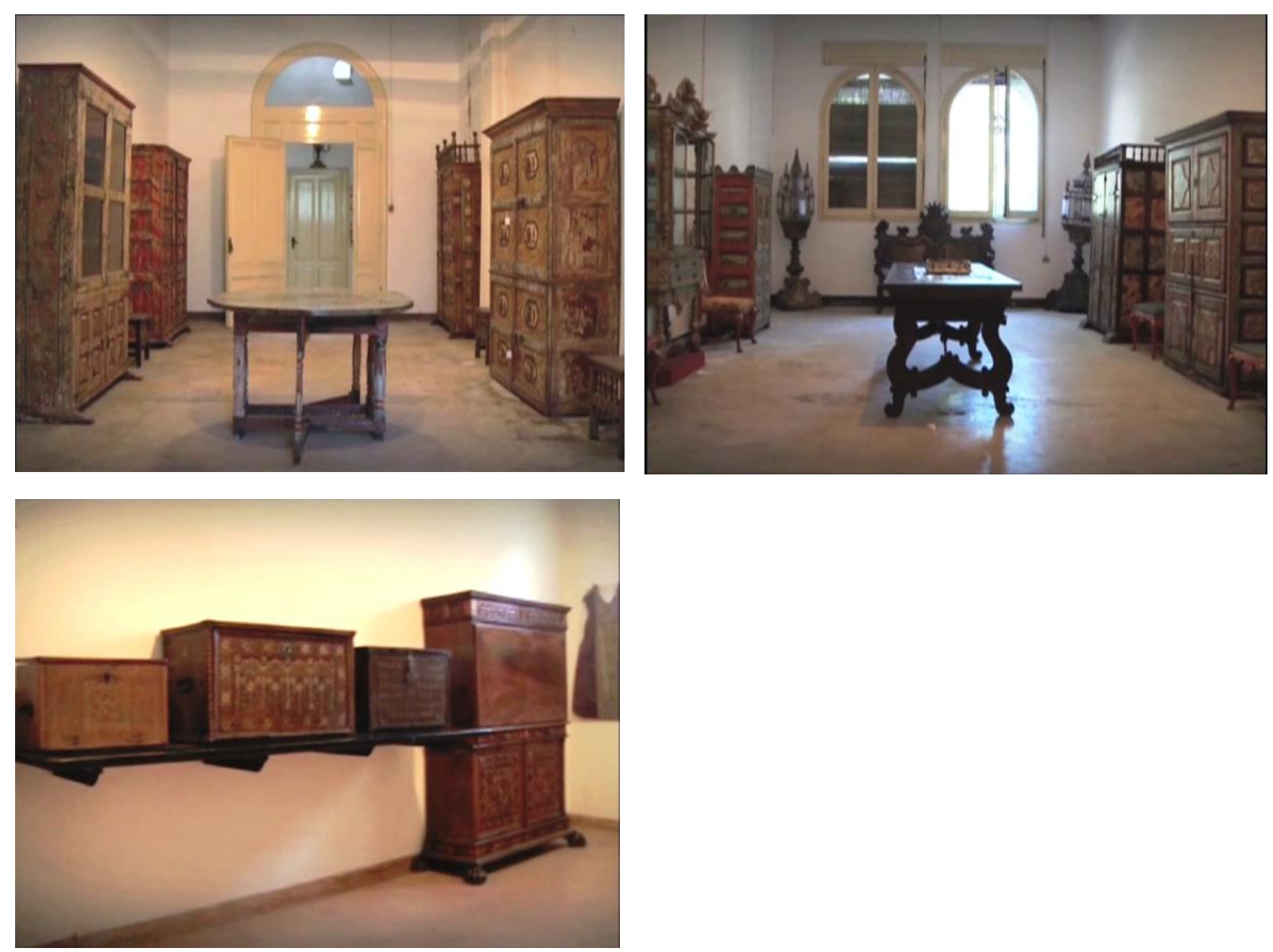

Fig. 10. Sala del antiguo laboratorio con armarios policromados, marmoleados y con arte povera.

Fig. 11. Otra sala del laboratorio con mobiliario de los siglos XVII y XVIII, tal como la Sra. Pla lo tenía colocado en vida.

Fig. 12. Vista de una parte de la colección de escritorios decorados con taracea y un escritorio con pie procedente de Valencia. 
Además de la calidad y la rareza, uno de los principales criterios de compra fue la pureza en el estado de conservación. Se podrá haber equivocado, como todo el que se arriesga, pero su objetivo era conseguir obras sin transformaciones o restauraciones excesivas. Quizás el detalle que mejor define la selección de piezas que hizo es que siendo una colección de muebles, y siendo el mueble francés el más reconocido y valorado mundialmente, a ella no le interesó. Tenía únicamente una cómoda regencia, preciosa, eso sí, pero nada más. Y si algo se hubiera querido vender eran los escritorios de carey, esos opulentos muebles barrocos que mantenía porque como coleccionista de escritorios "los tengo que tener", argumentaba. Y es que si una colección es el espejo de una persona, todo lo que respiraba lujo, dorados y sofisticación era ajeno a la señora Pla. La misma modestia que definió su vida se refleja en su legado, lleno de obras sencillas, que laten y representan el hacer y la vida de los pueblos.

Aunque numéricamente las tallas y la orfebrería ocupan un lugar menor, no así en calidad. Una selección excelente de obras igualmente de la Edad Moderna que ayudaban a crear la ambientación adecuada. Sobre los muebles, colgadas en la pared unas obras refuerzan el interés de las otras y se complementan.

Desde la Asociación para el Estudio del Mueble hemos homenajeado a esta mujer, que siempre hemos admirado por su entusiasmo y vivacidad, así como por haber dejado en la ciudad este enorme patrimonio de muebles. Ella nos abría las puertas para compartir la colección, comentar experiencias, discutir sobre la calidad de una obra, la antigüedad de otra. La discreción fue la virtud de una mujer que consideraba que la indiscreción era uno de los peores defectos que puede tener un hombre. Por ello, aunque ha abierto con generosidad su casa, consideraba que ella como persona no era protagonista y así no se dejaba fotografiar ni filmar.

Bonaventura Bassegoda comenta que el compromiso de un coleccionista es "escoger y querer unos objetos singulares y preciosos, rescatarlos y darles un lugar y un sentido nuevos. De esta manera la pieza adquirida entra en diálogo con otros objetos, pasa a formar parte de una serie o de un conjunto el sentido del cual sólo es conocido plenamente por su creador"10. Nosotros compartimos este parecer y queremos que el sentido que la señora Pla dio a su colección sea conocido y compartido.

La Asociación para el Estudio del Mueble desea ayudar al difícil objetivo de conservar en buen estado la colección y acercarla al público, sin dañar la esencia que la hizo posible. Igualmente cree que es necesario que la fundación encuentre el equilibrio que haga posible la convivencia dentro del edificio de los dos discursos esenciales, la colección de muebles y la historia del instituto médico. Pero aún más, la fundación, que lleva el nombre de su padre, tiene que apuntar alto y conseguir que este magnífico conjunto sea conocido y reconocido en los foros internacionales. Para lograr estos objetivos es imprescindible redactar un proyecto integral, y trabajar a fondo y en serio para hacerlo posible. El objetivo ha de ser de máximos y la metodología rigurosa. De momento, la Asociación para 
el Estudio del Mueble ha formado a los guías que explican la parte de la colección que es visitable; pero queda todo por hacer.

Las dificultades para lograr estas aspiraciones son de muchos tipos, pero hay una, la de la incomprensión del mueble, en la que nosotros estamos trabajando desde hace años. Mario Praz se debió morder la lengua cuando una amiga le preguntó ¿Cómo se pueden amar pedazos de madera?, pero Nuria Pla echo a patadas de su casa a representantes de cultura cuando, tras visitar la colección, sólo supieron decir "aquí únicamente hay madera y hierro". Esperemos, como deseaba ella, que este proyecto de fundación abierta al público avance para convertirse en un centro de referencia en los estudios de mueble, teniendo la colección como eje de la entidad y para que permita a muchos disfrutar de lo que ella creó.

\section{NOTAS}

${ }^{1}$ RUSIÑNOL, Santiago, Mis hierros viejos, conferencia leída en el Ateneu Barcelonés el 21/1/1893.
${ }^{2}$ El culto al objeto, Associació per a l'Estudi del Moble y Museu de les Arts Decoratives de Barcelona, Barcelona, 2010.

${ }^{3}$ PRAZ, Mario, La casa de la vida, edición en castellano Random House Mondadori, 2004.

${ }^{4}$ Un ejemplo de coleccionista de muebles de tamaño grande es Andreu Colomer Munmany, quien recogió un interesante conjunto de obras realizadas en piel conservado en Vic, Osona, en un museo actualmente gestionado por el Museu Episcopal de Vic. Dentro de su selección, el mueble figura como protagonista.

5 Existen diferentes estudios sobre el instituto, incluida la tesis doctoral, firmada por Sara Lugo Marquez. LUGO, Sara, Ciencia, industria e ideología en la Cataluña del siglo XX. El Instituto Ravetllat-Pla (1919-1939), Centre d'Història de la Ciència, Facultat de Medicina, Universitat Autònoma de Barcelona, Bellaterra, 2011.

${ }^{6}$ Sobre la composición de la colección de la señora Pla es imprescindible la consulta del único artículo sobre el tema de la mano de Miguel Angel Alarcia, historiador del arte y amigo personal de la coleccionista, quien pudo estudiar las obras junto a ella. ALARCIA, Miquel Angel, "La Col·lecció Núria Pla Montseny de la Fundació Ramon Pla Armengol" en Mercat de l'Art, col-leccionisme i museus. Estudis sobre el patrimoni artístic a Catalunya als segles XIX $i$ XX, pp. 13-23.

${ }^{7}$ Una selección de muebles de la colección Pla fueron estudiados de manera muy didáctica por Miguel Angel Alarcia y publicados en la sección "Conocer el mueble" en los fascículos de Planeta Agostini El mueble Antiguo, 1999.

${ }^{8}$ Ya en el año 1999, en nuestra publicación El mueble en Cataluña. El espacio doméstico del gótico al modernismo, Angle editorial, mostramos diversos muebles catalanes de la colección Pla. También incluimos ejemplares en la tesis doctoral, La calaixera o cómoda catalana y sus variantes tipológicas en el siglo XVIII, departamento de Historia del arte, Universidad de Barcelona, 2002; en el catálogo de la exposición El moble de l'Empordà al segle XVIII, Fundació Caixa de Girona, 2006, donde expusimos una cama policromada y en Audàcia i Delicadesa. El moble de Torroella de Montgrí i l'Empordà (1700-1800), Fundació Mascort, 2008, con traducción al castellano. Posteriormente, la Asociación para el Estudio del Mueble ha realizado diversos cursos teórico-prácticos a partir de muebles de la colección para ayudar a su conocimiento.

${ }^{9}$ M. Paz Aguiló ha dedicado diversos escritos a los muebles napolitanos en ébano y marfil que representan temas clásicos y a glorificar la dinastía de los Habsburgo. Su hipótesis sobre el escritorio de la colección Pla, que además llevó en exposición a la Biblioteca Nacional de Madrid, la plantea en AGUILÓ, M. Paz, “Regalos virreinales? A propósito de un mueble napolitano de 1609”, en Archivo Español de Arte, LXXIX, 316, octubrediciembre, 2006, pp. 403-425.

${ }^{10}$ BASSEGODA, Bonaventura, Mestres del dibuix català $i$ valencià. Artur Ramon, 2009 (opúsculo).

Fecha de recepción: 04-07-2017

Fecha de revisión: 18-09-2017

Fecha de aceptación: 18-12-2017 